\title{
Steam Treatment of Waste Polylactid Acid (PLA) Based Products for Lactic Acid Recovery
}

César M. Moreira, Ph.D. ${ }^{1},{ }^{2}$, Abhay Koppar, Ph.D. ${ }^{1},{ }^{3}$, Pratap Pullammanappallil, Ph.D. ${ }^{1}$, Bruce A. Welt, Ph.D. ${ }^{1}$

${ }^{1}$ ABE - Agricultural and Biological Engineering Department, University of Florida, Gainesville, FL 32611, USA, pcpratap@ufl.edu, bwelt@ufl.edu

${ }^{2}$ ESPOL Escuela Superior Politécnica del Litoral, Facultad de Ingeniería Mecánica y Ciencias de la Producción, Campus Gustavo Galindo, Km 30.5 Vía Perimetral, P.O. Box 09-01-5863 Guayaquil, ECUADOR, cemoreir@espol.edu.ec

${ }^{3}$ University of Denver, Daniels College of Business, 2101 S. University Blvd, Denver, Colorado 80208, USA, abhay.koppar@du.edu

\begin{abstract}
Thermal treatment of 2.5 grams (dry weight) and 7.5 grams (dry weight) batches of Polylactic acid (PLA)-product waste was carried out at $121 \mathrm{oC}$ and $160 \mathrm{oC}$ and exposed to different treatment time periods. Molecular weight reduction was not affected by the amount of PLA material loaded. Rate of molecular weight reduction was about six times faster at 160 oC than at 121 $o C$. Complete depolymerization of the PLA-product waste was not possible at the temperatures used here. A maximum recovery (yield) of lactic acid of $35 \%$ was obtained at a loading of $7.5 \mathrm{~g}$, temperature at $121^{\circ} \mathrm{C}$ and exposure time of 720 min. At $160^{\circ} \mathrm{C}$, recovery was $25 \%$ but obtained within 120 minutes. Results suggest that PLA-product waste behaviour will differ from pure PLA pellet. With PLA-product waste complete lactic acid recovery was not possible and other by-products like acetic and propionic acids were produced from thermal treatment. acid

Keywords-Steam hydrolysis, PLA, first order kinetics, lactic
\end{abstract}

Digital Object Identifier (DOI):

http://dx.doi.org/10.18687/LACCEI2016.1.1.354

ISBN: 978-0-9822896-9-3

ISSN: 2414-6390

$14^{\text {th }}$ LACCEI International Multi-Conference for Engineering, Education, and Technology: "Engineering Innovations for Global Sustainability", 20-22 July 2016, San José, Costa Rica. 


\section{Steam Treatment of Waste Polylactid Acid (PLA) Based Products for Lactic Acid Recovery}

César M. Moreira, Ph.D. ${ }^{1,2}$, Abhay Koppar, Ph.D. ${ }^{1,3}$, Pratap Pullammanappallil, Ph.D. ${ }^{1}$, Bruce A. Welt, Ph.D. ${ }^{1}$

${ }^{1}$ ABE - Agricultural and Biological Engineering Department, University of Florida, Gainesville, FL 32611, USA,pcpratap@ufl.edu,bwelt@ufl.edu

${ }^{2}$ ESPOL Escuela Superior Politécnica del Litoral, Facultad de Ingeniería Mecánica y Ciencias de la

Producción, Campus Gustavo Galindo, Km 30.5 Vía Perimetral, P.O. Box 09-01-5863 Guayaquil, ECUADOR, cemoreir@espol.edu.ec

${ }^{3}$ University of Denver, Daniels College of Business, 2101 S. University Blvd, Denver, Colorado 80208, USA, abhay.koppar@du.edu

\begin{abstract}
Thermal treatment of 2.5 grams (dry weight) and 7.5 grams (dry weight) batches of Polylactic acid (PLA)-product waste was carried out at $121{ }^{\circ} \mathrm{C}$ and $160^{\circ} \mathrm{C}$ and exposed to different treatment time periods. Molecular weight reduction was not affected by the amount of PLA material loaded. Rate of molecular weight reduction was about six times faster at $160{ }^{\circ} \mathrm{C}$ than at 121 ${ }^{\circ} \mathrm{C}$. Complete depolymerization of the PLA-product waste was not possible at the temperatures used here. A maximum recovery (yield) of lactic acid of $35 \%$ was obtained at a loading of $7.5 \mathrm{~g}$, temperature at $121{ }^{\circ} \mathrm{C}$ and exposure time of $720 \mathrm{~min}$. At $160^{\circ} \mathrm{C}$, recovery was $25 \%$ but obtained within 120 minutes. Results suggest that PLA-product waste behaviour will differ from pure PLA pellet. With PLA-product waste complete lactic acid recovery was not possible and other by-products like acetic and propionic acids were produced from thermal treatment.
\end{abstract} acid

Keywords-Steam hydrolysis, PLA, first order kinetics, lactic

\section{INTRODUCTION}

Regions in Latin America and Caribbean are becoming rapidly urbanized, due to economic growth. Recent World Bank studies projected that the region's municipal solid waste will increase from 131 million tons in 2005 to roughly 179 million in 2030 [1]. Effective municipal waste management practices are limited in developing world causing health problem and potent greenhouse gas (GHG) emissions [2]. Latin America generates more than 369,000 tons of urban waste daily [3]. Of this total, $56 \%$ is generated in large cities, $21 \%$ in the intermediate cities and $23 \%$ in small cities with $60 \%$ of the total being residential waste on average [4]. The composition of the municipal waste in Latin America region was reported to be: Organics - 54\%, Metal - 2\%, Glass $-4 \%$, Plastics - 12\%, Paper - 16\%, other $16 \%$ [4]. Based on this composition Latin America

Digital Object Identifier (DOI): http://dx.doi.org/10.18687/LACCEI2016.1.1.354 ISBN: 978-0-9822896-9-3

ISSN: 2414-6390 and Caribbean countries generate approximately 16 million tons of plastic per year.

Plastic is used in variety of daily use products as well as widely employed in many types of packaging throughout the world. The plastic waste is notoriously hard to degrade in landfills or is non compostable and is viewed as a serious environmental liability. In an effort to relieve the real or perceived environmental burden of petroleum-based polymers, work is being done to develop biologically derived plastics that are biodegradable. Examples include plastics derived from starch, polylacticacid (PLA) and polyhydroxybutyrates (PHB). Polylactic acid, is produced from renewable resources (currently from corn starch in the USA by Nature Works) and has recently experienced increased utilization as an alternative to petroleum derived polymers in order to reduce their impact on the environment [5].

PLA belongs to the family of aliphatic polyesters commonly made from ó-hydroxy acids and are considered biodegradable and compostable. PLA is a polyester polymer produced by the condensation of lactic acid derived from microbial fermentation of renewable agriculture resources, such as starch from corn, sucrose from cane sugar, lactose from cheese whey, and cellulose from waste papers [6]. PLA is thermoplastic, with high strength and high modulus, which makes it useful for the industrial packaging or the biocompatible/bioabsorbable medical device market. It is one of the few polymers in which the stereochemical structure 
can easily be modified by polymerizing a controlled mixture of the L- or D- isomers to yield high molecular weight amorphous or crystalline polymers that can come in contact with food and are generally recognized as safe [7].

Currently, large quantities of discarded PLA cups and containers are treated like any other plastic and transported to landfills because most municipalities do not possess expertise or equipment to handle PLA based products. But this "biodegradable" plastic does not degrade quickly in landfills. Studies on the effect of microorganisms found in landfills on degrading unused PLA films indicated that after 20 months the PLA was not fully degraded [8]. However, PLA based materials have been shown to be compostable wherein complete degradation was achieved in 35 days [9]. During composting the organic matter is converted to carbon dioxide and water, and does not recover or generate value-added products from the waste. Thermal treatment (whether using moist heat like steam or dry heat as in pyrolysis) of PLA has been employed for this purpose.

Hydrolysis is the chemical process that uses water to split polymer bonds, causing material decomposition to monomeric units. The polymer must contain hydrolysable covalent bonds such as ester, ether, anhydride, amide, carbamide (urea), ester amide (urethane) etc. PLA degrades in the presence of water due to the hydrolysis of its ester bonds [12]. Rate and extent of hydrolysis depends on parameters such as size and shape of the particle, the isomer ratio, temperature, water activity, $\mathrm{pH}$ and reaction time $[7,10]$. Poly L-lactic acid (PLLA) pellets when exposed to high pressure steam at temperatures between 100 and $130{ }^{\circ} \mathrm{C}$ resulted in rapid degradation as measured by change in molecular weight of hydrolysate [11]. In another study, PLLA beads when subjected to hydrolysis at temperatures ranging from 120 to $160{ }^{\circ} \mathrm{C}$ resulted in recovery of $90 \%$ of its lactic acid [12]. The recovered lactic acid can be used as a raw material to manufacture lactate esters via esterification with a combination of ethanol and pervaporation [13], propylene glycol via hydrogenation $[14,15,16]$ and to acrylate via dehydration $[17,18,19]$. The esters are described as non-volatile, non-toxic and biodegradable with solvent properties. Propylene glycol is a commodity chemical with a 1 billion pound per year market and is used as a low-toxicity antifreeze and deicer. Acrylates are noted for their transparency and elasticity.

Several studies on hydrolysis of lactic acid with moist heat (steam) that have been published in literature utilized the pure lactide form of PLA as raw material with the objective of elucidating mechanisms and kinetics of degradation [11, 12, 20, $21,22]$. The aim of this work was to investigate the effect of steam treatment temperature and loading, to hydrolyze polylactic acid (PLA) based consumable products (specifically cups), and evaluate the performance of the process in terms of kinetics of molecular weight reduction, extent of degradation, and lactic acid yield and selectivity.

\section{MATERIAL AND METHODS}

\section{A. Feedstock}

PLA waste was created using commercial thermoformed cups (Fabri-Kal, Inc., Kalamazoo, MI) obtained from The Training, Research and Education for Environmental Occupation (TREEO) Center at the University of Florida.

\section{B. Feedstock Preparation}

Two packets of 50 cups each were ground in a hammer mill. Larger pieces remaining after grinding were cut manually until all pieces were uniform size of approximately $2.5 \mathrm{~cm} \mathrm{X} 0.5 \mathrm{~cm}$.

\section{Treatment protocol}

To perform heat treatment, a Mathis BFA-24 Dye Beaker system with Univision PLC (Werner Mathis USA Inc., Concord, NC) was used. Treatment was conducted by depositing 2.5 or 7.5 grams of ground PLA in each Mathis BFA-24 $200 \mathrm{~mL}$ canister (working pressure 4 bar) along with 30 grams of deionized water. The canisters were purged for 2 minutes using nitrogen gas, tightly sealed, and then loaded into the equipment. Treatment was 
conducted at two temperatures, 121 and $160{ }^{\circ} \mathrm{C}$. The reaction duration was $120,240,360,480$ and 720 minutes at $121^{\circ} \mathrm{C}$, and $30,45,60,90$ and 120 minutes at $160{ }^{\circ} \mathrm{C}$. All experiments were duplicated. At the end of treatment duration, the canisters were allowed to cool down. The canister contents after treatment will henceforth be referred as "hydrolysate". After cooling to room temperature, $15 \mathrm{~mL}$ of liquid hydrolysate sample was taken from each canister and filtered using Whatman syringe $0.45 \mu \mathrm{m}$ filters. Two $\mathrm{mL}$ of the filtered liquid was placed into a clear borosilicate glass screw-neck vial $(12 \times 32 \mathrm{~mm})$ for lactic acid determination. The rest of the canister contents including solids was placed in an oven at $95{ }^{\circ} \mathrm{C}$ for 48 hours to drive off water. Dry solids were removed from the oven and a $10 \mathrm{mg}$ sample weighed and placed in a $10 \mathrm{~mL}$ screw-neck Pyrex vial, tetrahydrofuran (THF) HPLC grade solvent was added to each vial. This sample was used for molecular weight determination.

\section{Organic Acid determination}

Concentrations of organic acids like lactic acid, succinic acid, acetic acid, propionic acid and butyric acid was determined using a Merck Hitachi Elite LaChrome HPLC system (Hitachi, L2400, Tokyo, Japan) and a Bio-Rad Aminex HPX-87H column (Bio-Rad Laboratories) following procedures outlined in Muck and Dickerson [23]. The mobile phase used was a solution of sulfuric acid. Samples treated at 121 , and $160^{\circ} \mathrm{C}$ for more than 360 and 60 minutes respectively needed to be diluted to reduce viscosity. Only lactic acid, acetic acid and propionic acid was detected in the samples. These concentrations were zero for the solid sample at time $\mathrm{t}=0$

\section{E. Molecular weight determination}

A Waters GPCV2000 gel permeation chromatograph with an array of detection systems (UV/Vis, refractive index, light scattering, and differential viscometry) was used to determine molecular weight. Untreated and treated samples were dissolved in $10 \mathrm{ml}$ Tetrahydrofuran (THF), agitation and mild heat was used to completely

Digital Object Identifier: (to be inserted by LACCEI). dissolve the sample. Then the solution was filtered through $0.22 \mathrm{ml}$ syringe filter to remove any undissolved materials before injections. Fifty $\mu \mathrm{L}$ filtered solution was injected in each run, temperature was set at $25{ }^{\circ} \mathrm{C}$ and the flow rate was $1 \mathrm{~mL} / \mathrm{min}$. All results were processed using ChemStation software package with gel permeation chromatography (GPC) analysis (Rev.B.04.03). The molecular weight was calculated based on a universal calibration using a set of polystyrene standards [24]. A blank sample containing THF only, was run as a standard.

\section{RESULTS}

The average molecular weight of PLA based thermoformed cups used in this study was 120,871 $\mathrm{g} / \mathrm{mol}$. Figures $1(\mathrm{~A}, \mathrm{~B})$ and $2(\mathrm{~A}, \mathrm{~B})$ show the changes in the molecular weight for the two treatment temperatures at the two loadings (each data point is an average of two measurements from duplicate experiments). Error bars are not shown as these fall within the size of the symbols.

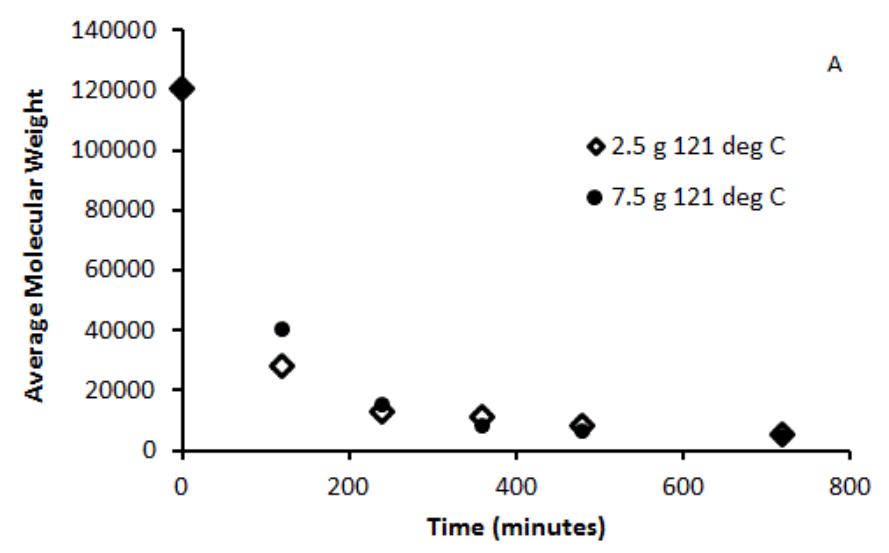




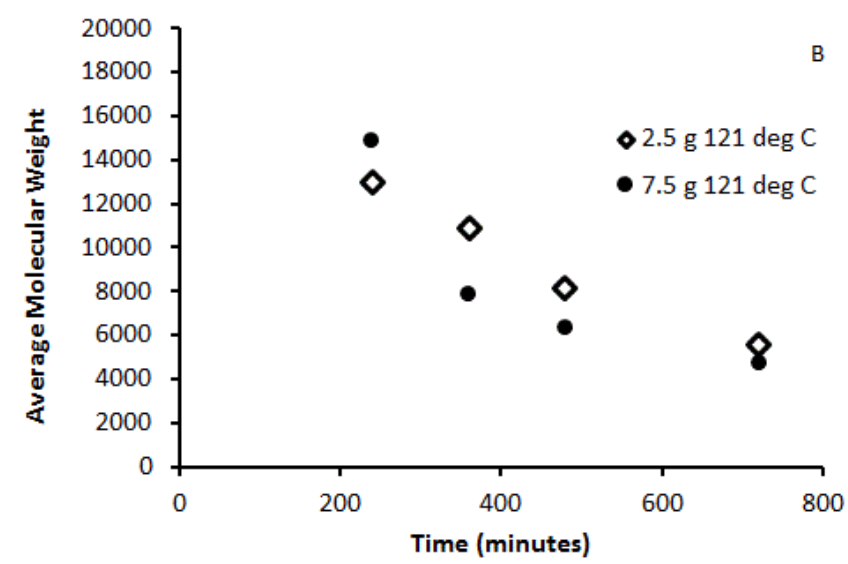

Figure 1. Change in average molecular weight of hydrolysate during treatment at $121^{\circ} \mathrm{C}$ for loading of $2.5 \mathrm{~g}$ and $7.5 \mathrm{~g}$. Data points are average of two experiments. A: Complete duration. B: drawn on enlarged scale to show changes in molecular weight towards later stages of treatment.

Figure 1 (A, B) corresponds to treatment temperature of $121{ }^{\circ} \mathrm{C}$, and Figure $2(\mathrm{~A}, \mathrm{~B})$ for temperature of $160{ }^{\circ} \mathrm{C}$. In all cases a reduction in molecular weight was observed.

At $121{ }^{\circ} \mathrm{C}$, for the treatment with $2.5 \mathrm{~g}$ loading, molecular weight decreased rapidly to $2.8 \times 10^{4}$ in 120 minutes and continued to decrease further to $1.09 \times 10^{4}$ grams at 360 minutes. At the end of the run (720 minutes) molecular weight was $5.57 \times 10^{3}$ grams. Similar observations were noted for treatment with $7.5 \mathrm{~g}$ loading. After 720 minutes the molecular weight was $4.7 \times 10^{3}$.

Figure 2 (A, B) summarizes average molecular weight changes at $160{ }^{\circ} \mathrm{C}$ for experiments loaded with $2.5 \mathrm{~g}$ and $7.5 \mathrm{~g}$ PLA, respectively.

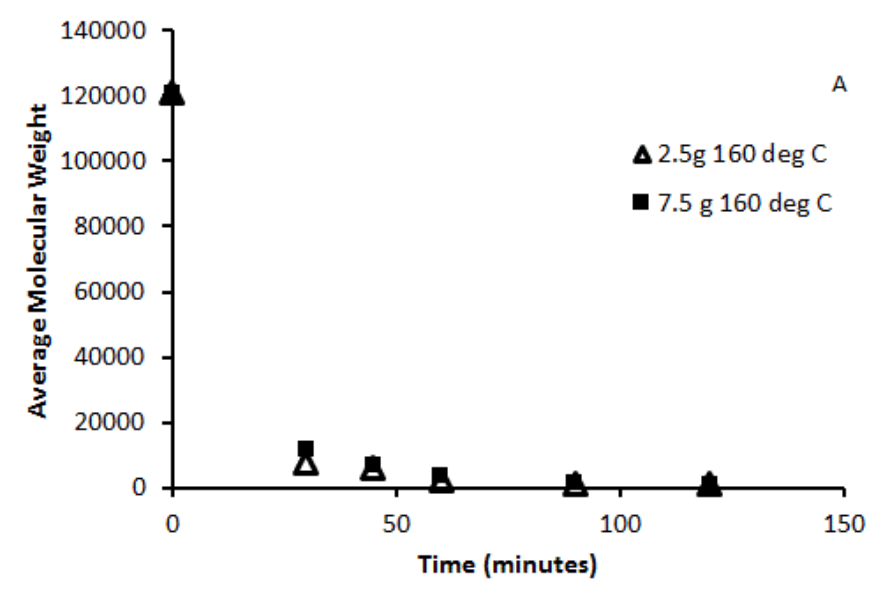

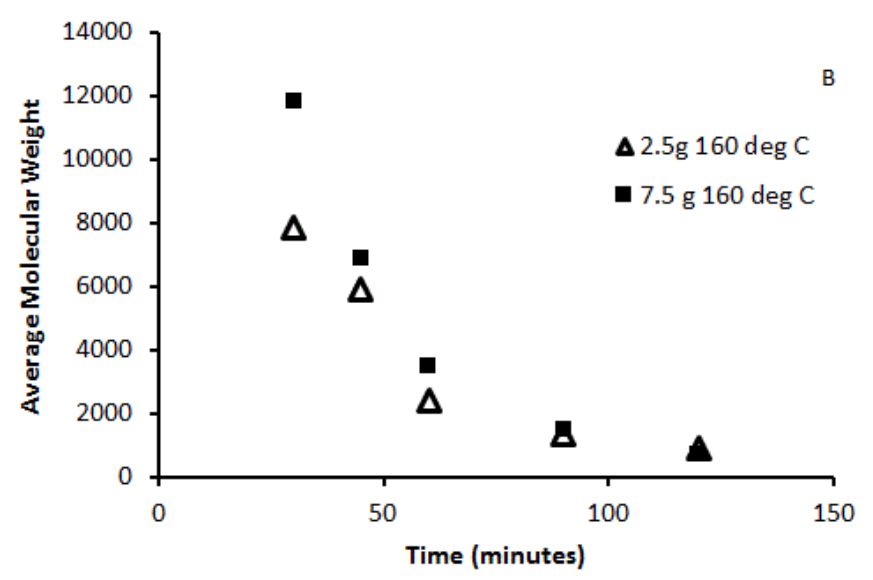

Figure 2. Change in average molecular weight of hydrolysate during treatment at $160{ }^{\circ} \mathrm{C}$ for PLA loading of $2.5 \mathrm{~g}$ and $7.5 \mathrm{~g}$. Data points are average of two experiments. A: Complete duration. B: drawn on enlarged scale to show changes in molecular weight towards later stages of treatment.

For samples with $2.5 \mathrm{~g}$ PLA the molecular weight decreased rapidly to $7.85 \times 10^{3}$ in 30 minutes and continued to decrease to $5.92 \times 10^{3}$ at 45 minutes.

At the end of the run (120 minutes) molecular weight dropped to $9.27 \times 10^{2}$. A similar observation was noted for treatment with $7.5 \mathrm{~g}$ loading. After 120 minutes, molecular weight decreased to $7.24 \times 10^{2}$

Figure 3 (A and B) shows the accumulation of lactic acid during treatment at $121^{\circ} \mathrm{C}$ (Figure 3A) and 160 ${ }^{\circ} \mathrm{C}$ (Figure 3B).

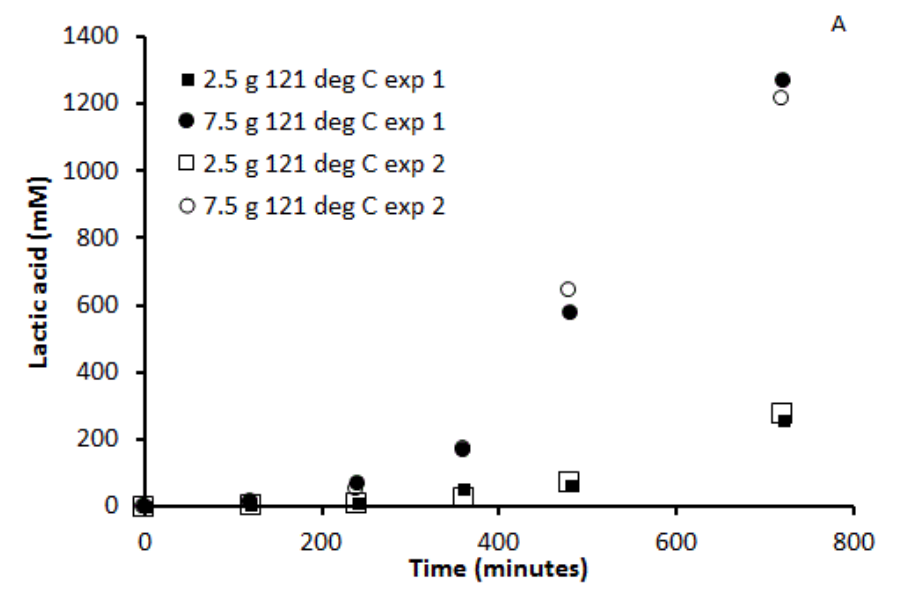




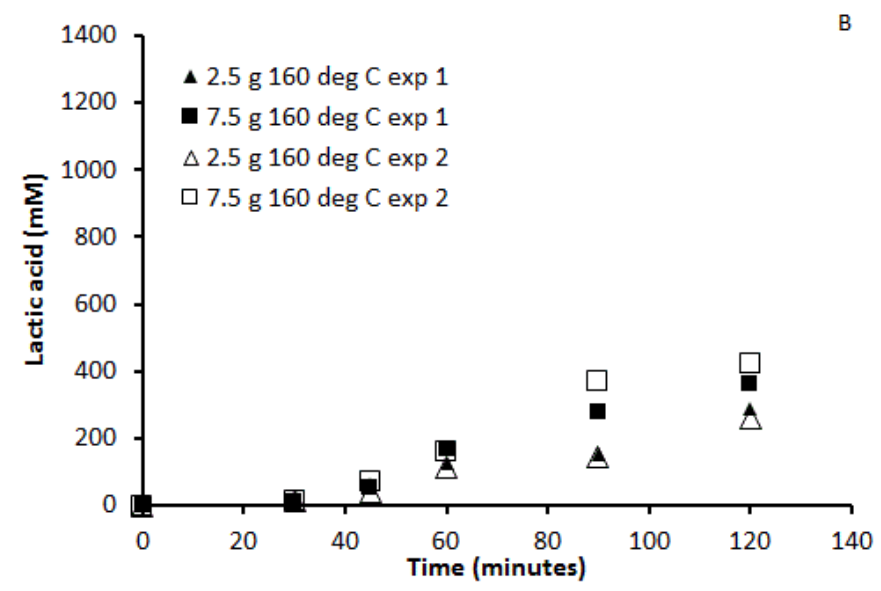

Figure 3. Accumulation of lactic acid during treatment at $\mathrm{A}: 121^{\circ} \mathrm{C}$, and $\mathrm{B}$ : $160{ }^{\circ} \mathrm{C}$ from duplicate experiments (exp 1 and 2 ) for $2.5 \mathrm{~g}$ and $7.5 \mathrm{~g}$ loading. Note: Ordinate scale are different due to differences in time exposure.

Data from duplicate experiments for each loading are shown in the figures. Lactic acid increased to 2.4 and $2.9 \mathrm{mM}$ within 120 minutes for treatment at $121{ }^{\circ} \mathrm{C}$ and $2.5 \mathrm{~g}$ loading. For $7.5 \mathrm{~g}$ loading the concentration after 120 minutes of treatment was 10.2 and $11.5 \mathrm{mM}$. The lactic acid continued to increase as treatment progressed reaching 50 and 26 $\mathrm{mM}$ after 360 minutes for $2.5 \mathrm{~g}$ loading, and 168 and $170 \mathrm{mM}$ for $7.5 \mathrm{~g}$ loading. After 720 minutes of treatment lactic acid concentrations were 258.6 and $273.6 \mathrm{mM}$ for $2.5 \mathrm{~g}$ loading, and 1270 and 1211 $\mathrm{mM}$ for $7.5 \mathrm{~g}$ loading. At $160{ }^{\circ} \mathrm{C}$ treatment, lactic acid increased to 10.6 and $11.2 \mathrm{mM}$ within 30 minutes for treatment at and $2.5 \mathrm{~g}$ loading. For $7.5 \mathrm{~g}$ loading the concentration after 30 minutes of treatment was 11.8 and $12.2 \mathrm{mM}$. The lactic acid continued to increase as treatment progressed reaching 125 and $115 \mathrm{mM}$ after 60 minutes for $2.5 \mathrm{~g}$ loading, and 166 and $159 \mathrm{mM}$ for $7.5 \mathrm{~g}$ loading. After 120 minutes of treatment lactic acid concentrations were 287.4 and $257.1 \mathrm{mM}$ for $2.5 \mathrm{~g}$ loading, and 360 and $424 \mathrm{mM}$ for $7.5 \mathrm{~g}$ loading.
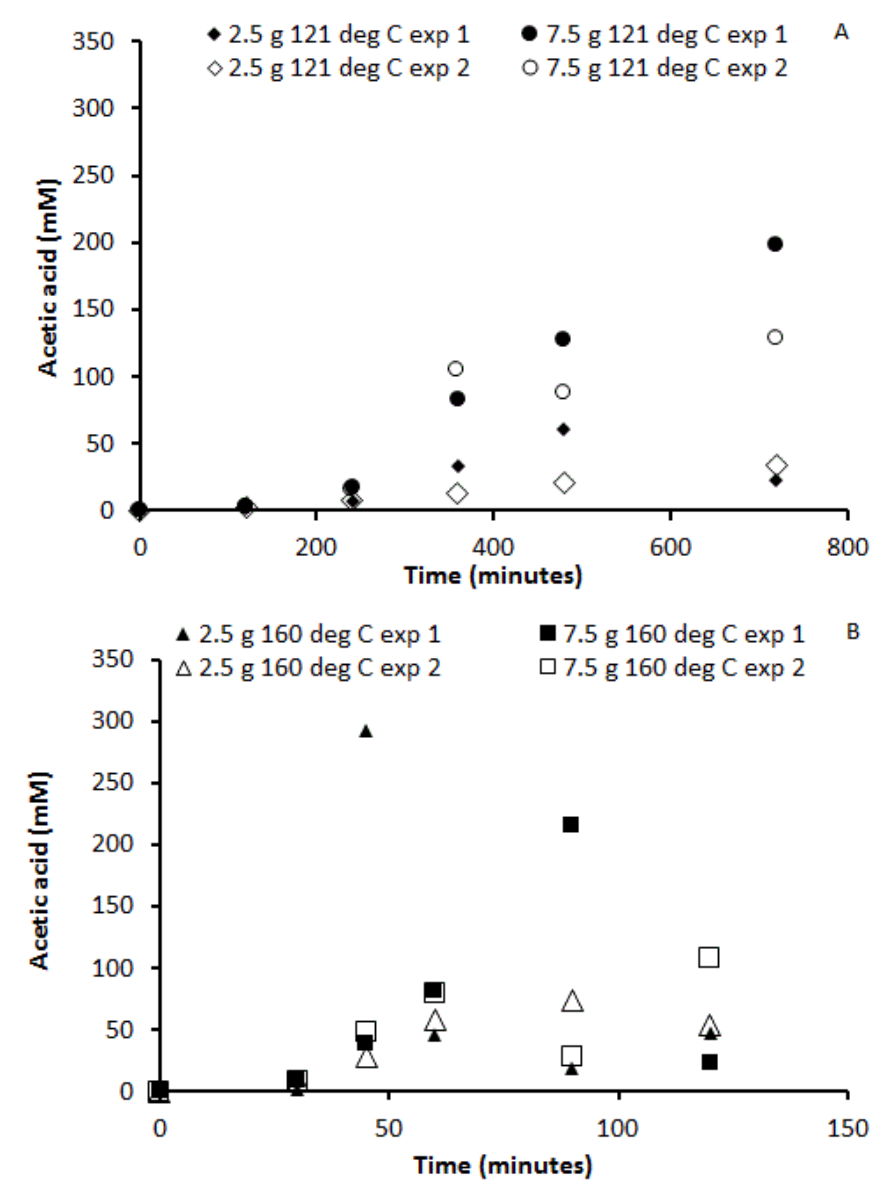

Figure 4. Acetic acid concentration during treatment at A: $121^{\circ} \mathrm{C}$ and B: 160 ${ }^{\circ} \mathrm{C}$ from duplicate experiments (exp 1 and 2) for 2.5 and $7.5 \mathrm{~g}$ loading. Note: Ordinate scale are different due to differences in time exposure.

In addition to lactic acid, acetic and propionic acids were also measured in the hydrolysates. Figure 4 depicts the concentrations of acetic acid in duplicate experiments for treatments at $121{ }^{\circ} \mathrm{C}$ (Figure 4A) and $160{ }^{\circ} \mathrm{C}$ (Figure 4B) and loadings of $2.5 \mathrm{~g}$ and 7.5 g. Like lactic acid, at both temperatures and loadings, acetic acid concentration increased after a lag phase. The duration of lag phase was about the same as for lactic acid. At $121^{\circ} \mathrm{C}$, acetic acid accumulated to $200 \mathrm{mM}$ and $125 \mathrm{mM}$ in the duplicate $7.5 \mathrm{~g}$ loading experiments.

In the $2.5 \mathrm{~g}$ experiment acetic acid increased to 50 $\mathrm{mM}$ and then dropped to $25 \mathrm{mM}$, and in the duplicate experiment it gradually increased to 30 $\mathrm{mM}$. At $160{ }^{\circ} \mathrm{C}$, acetic acid generally accumulated to between 50 and $100 \mathrm{mM}$, and fluctuated between 25 and $100 \mathrm{mM}$ at the end of the 2 hour treatment time. However, in two instances, acetic acid 
showed a sharp increase to $300 \mathrm{mM}$ within 45 minute of treatment and $2.5 \mathrm{~g}$ loading, and $215 \mathrm{mM}$ in 90 minutes of treatment and $7.5 \mathrm{~g}$ loading. Unlike lactic acid measurements in which duplicate experiments showed similar values of lactic acid concentration, the discrepancy between measurements of acetic acid concentration in duplicate experiments was large for many samples.

Figure 5 shows the concentration of propionic acid from the duplicate experiments at both temperatures and loadings. At $121{ }^{\circ} \mathrm{C}$ (Figure 5A) and $7.5 \mathrm{~g}$ loading propionic acid accumulation showed a very similar trend to acetic acid accumulation under the same treatment conditions.

But propionic acid only accumulated to $60 \mathrm{mM}$. Like acetic acid accumulation, for $2.5 \mathrm{~g}$ loading in one experiment propionic acid increased to $30 \mathrm{mM}$ and then dropped to $12 \mathrm{mM}$, whereas in the other duplicate experiment it gradually increased to 17 $\mathrm{mM}$ by the end of treatment. At $160{ }^{\circ} \mathrm{C}$ and $2.5 \mathrm{~g}$ loading in one experiment propionic acid accumulated to $40 \mathrm{mM}$ and then dropped to $15 \mathrm{mM}$ whereas in the duplicate experiment it increased to $27 \mathrm{mM}$ within 60 minutes then dropped to $10 \mathrm{mM}$ and again increased to $20 \mathrm{mM}$. In one of the $7.5 \mathrm{~g}$ loading experiment, propionic acid increased to 67 $\mathrm{mM}$ in 90 minutes and then dropped to $20 \mathrm{mM}$, whereas in the duplicate experiment it accumulate to $27 \mathrm{mM}$ in 60 minutes and then decreased to 7.5 $\mathrm{mM}$ by the end of treatment.

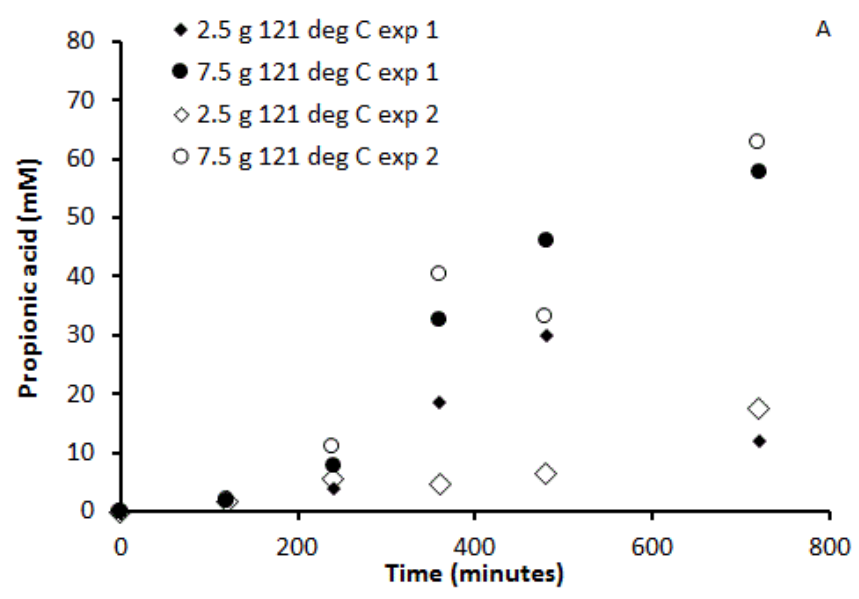

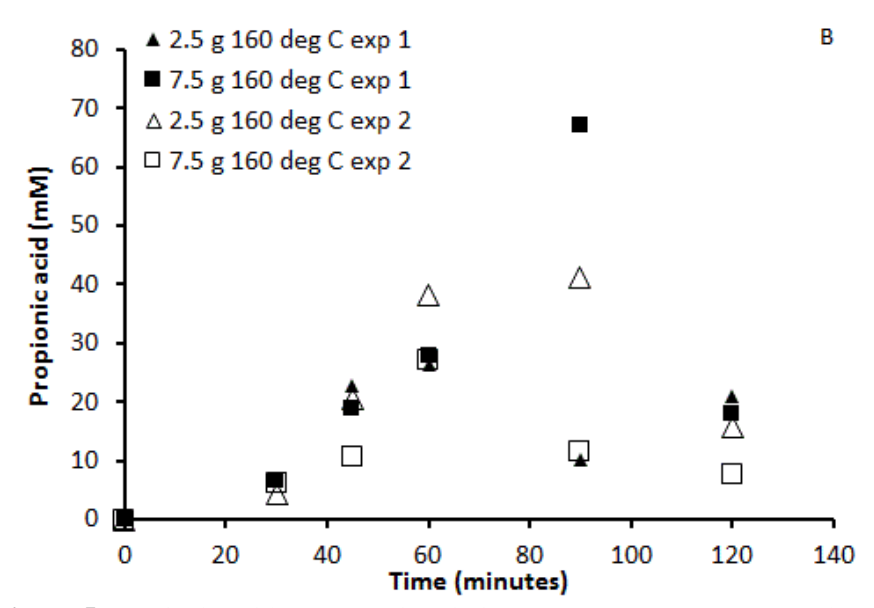

Figure 5. Propionic acid concentration during treatment at A: $121{ }^{\circ} \mathrm{C}$ and $\mathrm{B}$ : $160{ }^{\circ} \mathrm{C}$ from duplicate experiments (exp 1 and 2 ) for 2.5 and $7.5 \mathrm{~g}$ loading. Note: Ordinate scale are different due to differences in time exposure.

\section{Discussion}

\section{Molecular weight reduction}

The average molecular weight of 120,871 for the PLA based product determined in the present study agrees well with literature value of 120,000 $\mathrm{g} / \mathrm{mol}$ (number averaged molecular weight) reported for PLA (4042D) from Nature Works, USA [25]. Literature suggests that moisture breaks the ester bonds of PLA producing a reduction in chain size. Molecular weight decreased rapidly within 120 minutes of treatment at $121{ }^{\circ} \mathrm{C}$ and within 30 minutes of treatment at $160{ }^{\circ} \mathrm{C}$. After this, a more gradual decrease in molecular weight was observed for both temperatures. At both temperatures, it does not appear the polymer would completely degrade to smaller monomeric units. At $121{ }^{\circ} \mathrm{C}$, the molecular weight asymptotically approaches about 5000 whereas at $160{ }^{\circ} \mathrm{C}$ it asymptotically approaches 900. Amount of polymer loaded at the start of trial does not seem to affect the kinetics of molecular weight reduction or the final molecular weight that treatment would yield. As observed in the present study, the rate of decrease of average molecular weight was much faster at higher temperature of $160{ }^{\circ} \mathrm{C}$ than at $121{ }^{\circ} \mathrm{C}$, and average molecular weight dropped to less than 1000 within two hours treatment at $160{ }^{\circ} \mathrm{C}$ whereas it decreased to only 5000 even after 12 hours treatment at $121^{\circ} \mathrm{C}$ [26]. At $121{ }^{\circ} \mathrm{C}$, there is likely formation of 
intermediate products that reduce the rate of hydrolysis. Crystallinity and optical purity has been suggested as factors influencing hydrolysis kinetics [9].

\section{Kinetics of molecular weight reduction}

Based on results obtained of molecular weight reduction, it was proposed to fit a first order decay expression of the form

$\frac{d A}{d t}=-k\left(A-A_{f}\right)$

where

$\mathrm{A}$ is the average molecular weight at any time, $\mathrm{t}$ $\mathrm{k}$ is the first order decay constant $\left(\mathrm{min}^{-1}\right)$

$\mathrm{A}_{\mathrm{f}}$ is the eventual, average molecular weight of treatment products.

The above equation was integrated and expressed in a linear form as follows:

$\ln \left[\frac{A-A_{f}}{A_{o}-A_{f}}\right]=-k t$

where $A_{o}$ is the initial molecular weight $(120,871$ $\mathrm{g} / \mathrm{mol})$.

The Solver feature of MS-Excel was used to determine the optimum values of $\mathrm{A}_{\mathrm{f}}$ and $\mathrm{k}$ for each temperature. The optimum values were determined by minimizing the sum of squared errors between the linearized model fit and average molecular weight data at each temperature. Since there molecular weight decrease was not affected by the amount of PLA material loaded, data from both 2.5 and $7.5 \mathrm{~g}$ loading were averaged for each temperature. The linearized model for for molecular weight reduction at 121 and $160{ }^{\circ} \mathrm{C}$ is shown in Figure 6 . The figure also shows the $\mathrm{R}^{2}$ values, which indicates excellent model fits.

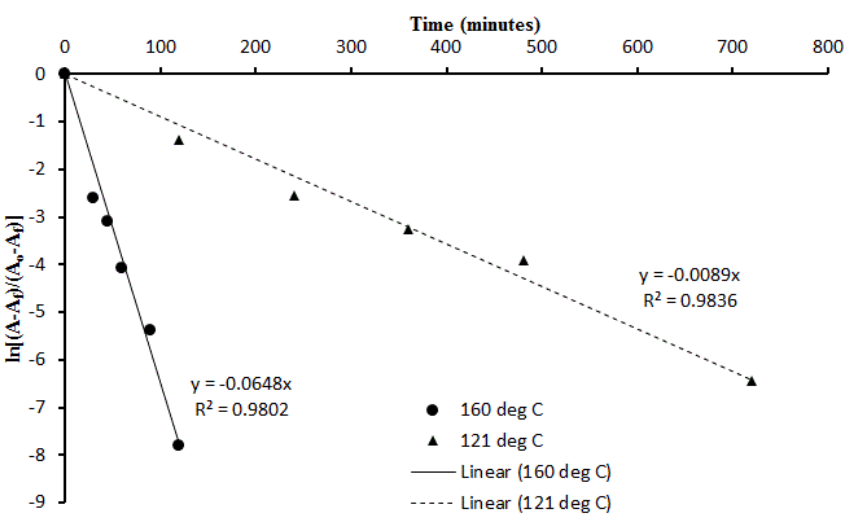

Figure 6. Linearized first order model for reduction in molecular weight as a function of treatment at 121 and $160^{\circ} \mathrm{C}$

Table 1, lists the kinetic parameters and $\mathrm{A}_{\mathrm{f}}$ values for treatment at 121 and $160{ }^{\circ} \mathrm{C}$. The temperature dependence of first rate constant was explored using the Arrhenius equation. From the fit to Arrhenius equation, the activation energy for depolymerisation was found to be $72.2 \mathrm{~kJ} / \mathrm{gmol}$ (Table 1). Exponential decay (or first order kinetics) adequately explains the complete profile for molecular weight reduction.

$$
\text { TABLE } 1 .
$$

KINETIC PARAMETERS FOR MOLECULAR WEIGHT REDUCTION DURING THERMAL TREATMENT OF PLA BASED MATERIALS.

\begin{tabular}{|c|c|c|c|}
\hline $\begin{array}{c}\text { Temperature } \\
\left({ }^{\circ} \mathrm{C}\right)\end{array}$ & $\begin{array}{c}\mathrm{K} \\
\left(\text { minutes }^{-1}\right)\end{array}$ & $\begin{array}{c}\mathrm{A}_{\mathrm{f}} \\
(\mathrm{g} / \mathrm{mol})\end{array}$ & $\begin{array}{c}\text { Activation energy } \\
\left(\mathrm{E}_{\mathrm{a}}, \mathrm{kJ} / \mathrm{gmol}\right)\end{array}$ \\
\hline 121 & 0.009 & 4946.82 & \multirow{2}{*}{72.2} \\
\hline 160 & 0.065 & 878.15 & \\
\hline
\end{tabular}

However, the eventual (equilibrium) product from treatment was a mixture of short chain oligomers, lactic acid and other by-products. The average molecular weight of the product mixture was lower at the higher treatment temperature. The average molecular weight would be 878 at $160{ }^{\circ} \mathrm{C}$, compared to about 5000 at $121{ }^{\circ} \mathrm{C}$. The activation energy calculated for the present study was close to a value of $75.2 \mathrm{~kJ} / \mathrm{gmol}$ reported in literature when working at a treatment temperature between 37-97 ${ }^{\circ} \mathrm{C}$ [20]. First order rate constants reported in literature were $0.005 \mathrm{~min}^{-1}$ at $100{ }^{\circ} \mathrm{C}$ and $0.043 \mathrm{~min}^{-}$ ${ }^{1}$ at $130{ }^{\circ} \mathrm{C}[9]$. Based on these rate constants the activation energy for study in [9] can be calculated as $89.9 \mathrm{~kJ} / \mathrm{g}$ mol and the rate constant at $121{ }^{\circ} \mathrm{C}$ would have been $0.023 \mathrm{~min}^{-1}$. This value would be about 2.5 times higher than values determined in the 
present study. The discrepancy could be due to the fact that, the study reported in [9] used pure PLA pellets whereas the present used a PLA based product which would have contained other additives.

\section{Lactic Acid Formation}

The monomer lactic acid was expected to be the final product from degradation of PLA polymers. Lactic acid is not produced immediately upon commencement of treatment, but there is a lag phase before lactic acid begins to accumulate. The duration of this lag phase is dependent on temperature of treatment. The lag phase was shorter at the higher temperature. Average duration of lag phase was about 250 minutes for treatment at $121{ }^{\circ} \mathrm{C}$ and about 30 minutes at $160{ }^{\circ} \mathrm{C}$. Lag phase duration was not influenced by amount loaded. Corresponding to molecular weight reduction, the rate of lactic acid accumulation was temperature dependent being faster at $160{ }^{\circ} \mathrm{C}$. Lactic acid concentration was dependent on amount of PLA loaded. At $121{ }^{\circ} \mathrm{C}$ by the end of 12 hours treatment, the average lactic acid concentration was $1240 \mathrm{mM}$ in canisters that contained $7.5 \mathrm{~g}$ of PLA whereas it accumulated to only $260 \mathrm{mM}$ in canisters that contained $2.5 \mathrm{~g}$ of PLA. At $160{ }^{\circ} \mathrm{C}$ treatment, average lactic acid concentration was $390 \mathrm{mM}$ in canisters that contained $7.5 \mathrm{~g}$ of PLA and $270 \mathrm{mM}$ in canisters that contained $2.5 \mathrm{~g}$ PLA material. Even though molecular weight degraded to lower values during $160{ }^{\circ} \mathrm{C}$ treatment, the amount of lactic acid accumulation was about the same compared to 121 ${ }^{\circ} \mathrm{C}$ in $2.5 \mathrm{~g}$ PLA loaded canisters. In the $7.5 \mathrm{~g}$ PLA loaded canisters lactic acid accumulated to much higher values during $121{ }^{\circ} \mathrm{C}$ treatment than at 160 ${ }^{\circ} \mathrm{C}$. In both treatments and loading lactic acid production had not completed when experiment was stopped.

Based on stoichiometry, for every gram of PLA hydrolyzed, $1.25 \mathrm{~g}$ of lactic acid should be produced. The mass of lactic acid in the canisters was calculated from the measured lactic acid concentration and the volume of liquid in the canister. The mass of lactic acid divided by the expected yield of lactic acid from 2.5 and $7.5 \mathrm{~g}$ loading (which is equal to $3.125 \mathrm{~g}$ and $9.375 \mathrm{~g}$ respectively) gives the selectivity for conversion to lactic acid. Figure 7 shows the selectivity to lactic acid in thermal treatment. As can be seen by the end of experiment at $160{ }^{\circ} \mathrm{C}$, average selectivity for lactic acid was around 0.25 whereas for treatment temperature of $121{ }^{\circ} \mathrm{C}$ it was 0.35 for $7.5 \mathrm{~g}$ loading and 0.05 for $2.5 \mathrm{~g}$ loading.

\section{Thermal treatment by-products}

In addition to lactic acid, other organic acids like acetic and propionic acids were also produced. These by products were not detected in thermal treatment studies conducted with pure PLA pellets $[7,12,23,27]$ In these studies at least $90 \%$ lactic acid was recovered.

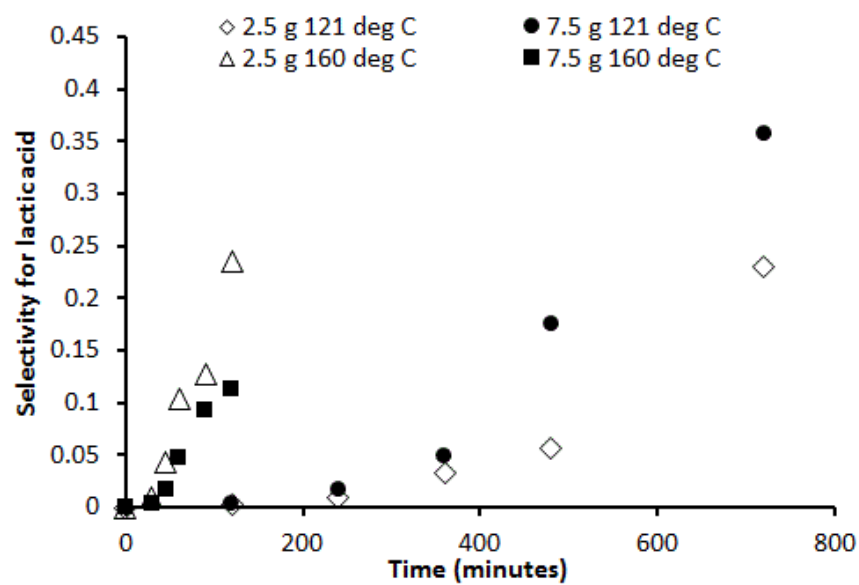

Figure 7. Average selectivity of conversion of PLA to lactic acid, during treatments at $121{ }^{\circ} \mathrm{C}$ and $160{ }^{\circ} \mathrm{C}$

Therefore, it appears that these by products are produced due to the presence of additives in the PLA based product. Products made from PLA may contain plasticizers and additives to increase stability [28]. Accumulation of both acetic acid and propionic acid followed the same lag duration as lactic acid at both temperatures indicating these are produced probably from the same precursors as lactic acid. Lactic acid is stable to thermal decomposition [29] Therefore, the by-products detected in this study were produced from PLA material rather than from decomposition of lactic 
acid. Both acetic and propionic acid appear to be degrading during treatment. At $160{ }^{\circ} \mathrm{C}$ it was degraded sooner within 50 to 100 minutes of treatment and at $121{ }^{\circ} \mathrm{C}$ degradation appears to occur after 500 minutes of treatment. These acids could be degraded to carbon dioxide and gas build up was observed when the canisters were opened after these were cooled to room temperature.

Thermal treatment process developed in this research is environmentally friendly in that it operates with water. No chemicals are added and no acid/ alkali, solvent, or enzymatic pretreatment is required. This reduces the capital cost of the process. Corrosion of equipment is no longer a major issue thereby reducing equipment maintenance costs. The process developed here can be scaled up to a modular system that will receive one day's collection of poly-lactic acid (PLA). The modular system will contain a steam generator, two hydrolyzers, holding tank, screw conveyor and a hammer mill. PLA will be fed to a hammer mill and pulverized to homogenous pieces. The pulverized PLA will be fed to the hydrolyzer via screw conveyor. One hydrolyzer will be filled while the other will be treating PLA waste. Once a hydrolyzer is charged with PLA, the steam from steam generator will be injected into the hydrolyzer. The valve will open after pre-set time period and hydrolysate (containing lactic acid) will be transferred to a holding tank. This procedure will be repeated daily.

\section{CONCLUSIONS}

PLA-product waste was thermally treated at $121{ }^{\circ} \mathrm{C}$ and $160{ }^{\circ} \mathrm{C}$, over a range of times at two different loadings. Molecular weight reduction was not affected by amount of PLA material loaded. Rate of molecular weight reduction was about six times faster at $160{ }^{\circ} \mathrm{C}$ than at $121{ }^{\circ} \mathrm{C}$. Complete depolymerization of the PLA-product waste was not possible at the temperatures used here. A maximum recovery (yield) of lactic acid of $35 \%$ was obtained at a loading of $7.5 \mathrm{~g}$, temperature at $121{ }^{\circ} \mathrm{C}$ and exposure time of $720 \mathrm{~min}$. At $160{ }^{\circ} \mathrm{C}$, recovery was $25 \%$ but obtained within 120 minutes. Results suggests that PLA-product waste behaviour will differ from pure PLA pellet. With PLA-product waste other by-products like acetic and propionic acids were produced from thermal treatment. Lactic acid will have to be separated from these byproducts and partially depolymerized oligomers for reuse and recycle.

\section{ACKNOWLEDGMENT}

The authors are much indebted to the cooperation of The Butler Polymer Laboratory especially Mr. Laurent Mialon (UF Chemistry Department), and Dr. Adegbola Adesogan Laboratory (UF Animal Science) in the performed analyses, also, to the GEM fellowship and the University of Florida Agricultural and Biological Engineering Department for their financial support.

\section{REFERENCES}

[1] Golders Associates. 2006. "Improving Management and Quality of Municipal Solid Waste Services." Report prepared for Finance, Private Sector, and Infrastructure Unit, Latin America and the Caribbean Region, World Bank, Washington, DC.

[2] Rebolledo, E. (2013). Case Study Brief: "Turning Waste into Resources: Latin America's Waste-to-Energy Landfills. Evidence and Lessons from Latin America (ELLA).

[3] Hoornweg, D. and Giannelli, N. (2007). "Managing municipal solid waste in Latin America and the Caribbean, Integrating the private sector, harnessing initiatives. Note no. 28, Public Private Infrastructure Advisory Facility (PPIAF), c/o The World Bank, 1818 H St., N.W., Washington, DC 20433.

[4] Martínez Arce, E., Daza, D., Tello Espinoza, P., Soulier F., Terraza Martin, H. (2010). Regional Evaluation on Urban Solid Waste Management in Latin America and the Caribbean: Report - by Pan American Health Organization (PAHO), the Inter-American Development Bank (IDB), and the Inter-American Association of Sanitary and Environmental Engineering (AIDIS).

[5] Tsuji, H., Saeki, T., Tsukegi, T., Daimon, H., \& Fujie, K. 2008. Comparative study on hydrolytic degradation and monomer recovery of poly(l-lactic acid) in the solid and in the melt. Polymer Degradation and Stability, 93(10), 1956-1963.

[6] Ho, K. G., Pometto III, A. L., \& Hinz, P. N. 1999. Effects of temperature and relative humidity on polylactic acid plastic degradation. Journal of Environmental Polymer Degradation, 7(2), 83-92.

[7] Garlotta, D. 2001. A literature review of poly(lactic acid). Journal of Polymers and the Environment, 9(2), 63-84.

[8] Tokiwa, Y., \& Jarerat, A. 2004. Biodegradation of poly(L-lactide). Biotechnol.Lett, 26, 771-777.

[9] Rudeekit, Y.., Numnoi, J., Tajan, M., Chaiwutthinan, P., and Leejarkpai L. Determining Biodegradability of Polylactic Acid under Different Environments. Journal of Metals, Materials and Minerals 18 (2), 83-87

[10] Lucas, N., Bienaime, C., Belloy, C., Queneudec, M., Silvestre, F., \& Nava-Saucedo, J.2008. Polymer biodegradation: Mechanisms and estimation techniques - A review. Chemosphere, 73(4), 429-442.

[11] Mohd-Adnan, A., Nishida, H., \& Shirai, Y. 2008. Evaluation of kinetics parameters for poly(l-lactic acid) hydrolysis under high-pressure steam. Polymer Degradation and Stability, 93(6), 1053-1058. 
[12] Chauliac, D., Development of a thermochemical process for hydorolysis of polylactic acid polymers to L-lactic acid and its purification using an engineered microbe. 2013, Doctoral Thesis, University of Florida.

[13] Delgado, P., Sanz, M. T., Beltrán, S., Núñez, L. A., (2010). "Ethyl lactate production via esterification of lactic acid with ethanol combined with pervaporation". Chemical Engineering Journal, Volume 165, Issue 2, Pg. 693 - 700.

[14] Delgado, P., Sanz, M. T., Beltrán, S., Núñez, L. A., (2010). "Ethyl lactate production via esterification of lactic acid with ethanol combined with pervaporation". Chemical Engineering Journal, Volume 165, Issue 2, Pg. 693 - 700.

[15] Simonov, M. N., Simakova, I. L., Parmon, V. N., (2009). "Hydrogenation of lactic acid to propylene glycol over coppercontaining catalysts" Reaction Kinetics and Catalysis Letters. Vol. 97, Issue $1, \mathrm{Pg} .157$ - 162.

[16] Zhang, M., Jackson, J. E., Miller, D. J., (2001). "Aqueous - phase hydrogenation of lactic acid to propylene glycol". Applied Catalysis A: General, Vol. 219, Pg. 89 - 98.

[17] Blanco, E., Loridant, S., Pinel, C., (2016). "Valorization of Lactic Acid and Derivatives to Acrylic Acid Derivatives: Review of Mechanistic Studies". Chapter; Reaction Pathways and Mechanisms in Thermocatalytic Biomass Conversion II, Part of series: Green Chemistry and Sustainable Technology, Pg. $39-62$.

[18] Peng, J., Li, X., Tang., C., Bai, W., (2014). "Barium sulphate catalyzed dehydration of lactic acid to acrylic acid". Green Chemistry, Vol. 16, Issue 1, Pg. 108 - 111. Ghantani, V. C., Lomate, S. T., Dongare, M. K., Umbarkar, S. B., (2013). "Catalytic dehydration of lactic acid to acrylic acid using calcium hydroxyapatite catalysts". Green Chemistry, Vol. 15, Issue 5, Pg. $1211-1217$.

[19] Tsuji, H., \& Ikarashi, K. 2004. In vitro hydrolysis of poly(L-lactide) crystalline residues as extended-chain crystallites: II. effects of hydrolysis temperature. Biomacromolecules, 5(3), 1021-1028

[20] Zhang, X., Wyss, U. P., Pichora, D., \& Goosen, M. F. A. 1994. An investigation of poly(lactic acid) degradation. Journal of Bioactive and Compatible Polymers, 9(1), 80-100.

[21] Salazar Gonzales, Romulo Vinicio, 2014. Impact of polylactide (PLA) on the quality of bio-products in contact. Doctoral Thesis, L'Institut des Sciences et Industries du Vivant et de l'Environnement, AgroParisTech.

[22] Muck, R. E., and J. T. Dickerson. 1988. Storage temperature effects on proteolysis in alfalfa silage. Trans. ASAE 31:1005-1009

[23] Wang, L., Tong, Z., Ingram, L., Cheng, Q., Matthews, S. 2013. Green Composites of Poly (Lactic Acid) and Sugarcane Bagasse Residues from Bio-refinery Processes. J Polym Environ 21:780-788

[24]Jandas, P.J., Mohanty, S. and Nayak, S. K. 2013. Rheological and mechanical characterization of renewable resource based high molecular weight PLA nanocomposites. Journal of Polymers Article ID 403467. Le Digabel, F., Avérous, L. 2006. Effects of lignin content on the properties of lignocellulose-based biocomposites. Carbohydrate Polymers 66 (2006) 537-545. http://dx.doi.org/10.1155/2013/403467

[25] Fan, Y., Nishida, H., Shirai, Y., Tokiwa, Y., Endo, T. 2004. Thermal degradation behaviour of poly (lactic acid) stereocomplex. Polymer Degradation and Stability 86:197-208

[26] Tsuji, H., Daimon, H., \& Fujie, K. 2003. A new strategy for recycling and preparation of poly(L-lactic acid): Hydrolysis in the melt. Biomacromolecules, 4(3), 835-840.

[27] Averous, L. 2008. Polylactic Acid: Synthesis, Properties and Applications. Belgacem MN, Gandini A, eds. Monomers, Polymers and Composites from Renewable Resources 433 - 450.

[28] de Villiers, M.M., Wurster, D. E and Narsai, K. 1997, Stability of lactic acid and glycolic acid in aqueous systems subjected to acid hydrolysis and thermal decomposition. J. Soc. Cosmet. Chem., 48,165-174

\section{$14^{\text {th }}$ LACCEI International Multi-Conference for Engineering, Education, and Technology: "Engineering Innovations for Global Sustainability", 20-22 July 2016, San José, Costa Rica.}

